\title{
Experimental investigation of the dynamic behavior of railway track with sleeper voids
}

\author{
Mykola Sysyn $^{1}$ (1) $\cdot$ Olga Nabochenko $^{2} \cdot$ Vitalii Kovalchuk $^{2}$
}

Received: 20 January 2020/Revised: 4 August 2020/Accepted: 6 August 2020/Published online: 27 August 2020

(C) The Author(s) 2020

\begin{abstract}
The deterioration of the sleeper support on the ballasted track begins with the accumulation of sleeper voids. The increased dynamic loading in the voided zone and the ballast contact conditions cause the accelerated growth of the settlements in the voided zones, which results in the appearance of local instabilities like ballast breakdown, white spots, subgrade defects, etc. The recent detection and quantification of the sleeper voids with track-side and onboard monitoring can help to avoid or delay the development of local instabilities. The present paper is devoted to the study of the dynamic behavior of railway track with sleeper voids in the ballast breakdown zone. The result of the experimental track-side measurements of rail acceleration and deflection is presented. The analysis shows the existence of the dynamic impact during wheel entry in the voided zone. However, the measured dynamic impact is subjected to the bias of the track-side measurement method. Both the mechanism of the impact and the measurement aspects are explained by using the one-beam model on viscoelastic foundation. The void features in the dynamic behavior are analyzed for the purpose of track-side and onboard monitoring. A practical method of the void parameter quantification is proposed.
\end{abstract}

Keywords Ballasted track - Sleeper voids - Ballast breakdown · Track-side measurement $\cdot$ Rail deflection . Dynamic modeling $\cdot$ Impact $\cdot$ Identification

Mykola Sysyn

mykola.sysyn@tu-dresden.de

1 Institute of Railway Systems and Public Transport, Technical University of Dresden (TUD), Dresden, Saxony, Germany

2 Department of the Rolling Stock and Track, Lviv Branch of Dniprovsk National University of Railway Transport, Lviv, Ukraine

\section{Introduction}

The ballast layer is one of the track elements that has the highest influence on track geometry quality and the maintenance costs that can reach up to $30 \%$ of the overall superstructure maintenance costs [1]. Ballasted track from the mechanical point of view is not the perfect structure due to a combination of the elastic elements like a sleeperrail grid with loose ballast material. Therefore, the residual reformations of the ballast layer in the contact with sleeper are inevitable, taking into account the initial inhomogeneity of the ballast layer, subgrade, and dynamic loadings. The sleeper voids are the first symptoms of the sleeper support deterioration phenomenon. The following ones are the track geometry errors, ballast breakdown up to subgrade settlements, and defects [2]. Thus, the recent sleeper voids identification, monitoring, and the following maintenance planning are a good way of the ballast-driven maintenance costs reduction.

One of the most extensive contributions in the research of the sleeper voids development is brought in the work [3], where the main influencing factors of the ballast settlement and the settlement mechanisms are taken into account. The developed complex model of the track short- and long-term dynamic behavior using hypoplastic law and FEM modeling was proposed for the voids prognosis. The work results indicate the complexity of the sleeper void deterioration mechanism as well as the necessity of the experimental data for the model calibration and verification. An experimental study of the void development process due to the full or the partial relief of the ballast pressure and vibrations is demonstrated in Ref. [4]. The study shows that the voids significantly influence the ballast settlement intensity, and thus, the voids have the self-accelerating effect. Lundqvist and Dahlberg [5] presented a theoretical 
study of the sleeper contact impact due to unsupported sleepers. It is found that one single hanging sleeper with $1 \mathrm{~mm}$ void can cause the sleeper-ballast contact force at the sleeper adjacent to the hanging one to increase by $70 \%$.

The dynamic behavior of railway track with different sleeper supports is presented in the investigations that are based on the holographic interferometry and acceleration measurements [6]. The in situ identification of the partially unsupported sleepers was performed using the multi-point acceleration measurements on the sleeper and the spectrum analysis. The analysis has shown that the deteriorated sleeper support is clearly detectable by structural dynamic parameters irrespective of the kind of the excitation. A similar investigation on the effects of ballast voids on free vibration response parameters of in situ railway concrete sleepers is presented in Refs. [7, 8]. The different partially supported void conditions were modeled using full-scale tests in the laboratory together with impact tests measurements of the free vibrations and FEM modeling. Both the experimental and the numerical results show that the voids have a significant effect on the rigid body dynamics and the first bending vibration of the voided sleepers.

Mathematical modeling of the dynamic behavior of railway track with sleeper voids is demonstrated in Refs. [9-14]. Reference [9] describes a flexible track system model that is integrated into a commercial railway vehicle dynamics software capable of taking time into account in the detailed calculation of the nonlinear ballast-sleeper interaction. The sleeper-gap interaction is described with a bilinear function. Rezaei and Dahlberg [10] presented analytical and finite element solutions to the problem of a vibrating beam, fully, or partly supported by an elastic foundation. The study shows that the lowest bending-mode eigenfrequencies are just slightly influenced by the foundation stiffness, whereas higher eigenfrequencies are affected very little by the foundation. The influence of railpad stiffness on the sleeper bending-mode eigenfrequencies is negligible. Zhu et al. [11] presented the development of a vehicle-track model assembly, which couples the integration of the continuous and discrete system. The model takes into account an uncontacted spring-damping element underneath the unsupported sleeper and the triangularly unsupported sleeper. The model was used to investigate the dynamic interaction between the wheel and the rail with unsupported sleepers. The results show that there exists a critical gap size, which causes the largest force variation. The critical gap size is estimated to $2.5 \mathrm{~mm}$ for four unsupported sleepers. An investigation on the effect of hanging sleepers on wheel and rail dynamic interaction in the heavy-haul railway is presented in Ref. [12] on the basis of the coupled vehicletrack dynamics model. The results show the estimation of the dynamics for the completely and incompletely hanging sleeper. Iterative modeling of long-term differential settlements that takes into account sleeper voids influence is presented in the theoretical study [13]. The short-term model is presented with the track finite element EulerBernoulli beam that is coupled with a three-piece bogie. The model was used for the study of the track irregularity evolution in the zone of the dipped weld under the influence of rail pad stiffness and the void depth. Numerical estimation of sleeper voids on the wheel force and ballast force in the transition zones between ballast and the slab track is shown in Ref. [14] using a 3D FEM model with a penalty-based contact between the sleeper and the ballast. An application of adjustable fasteners is proposed to exclude the sleeper voids up to $12 \mathrm{~mm}$ and thus for the reduction of dynamic loadings. The influence of the adjustable fasteners is estimated by up to $92 \%$ of the maximal wheel loading reduction.

The aspects of the structural health monitoring and diagnostics of the ballast support are presented in the studies [15-24]. The most recent studies are related to the track stiffness measurements using track-side or vehiclebased and track-based measurement systems. There are many examples of the stiffness measurement trains like Rolling Stiffness Measurement Vehicle of Swedish railway, The Chinese Track Stiffness Measurement System, American Track Loading Vehicle, Swiss Track Stiffness Measurement Vehicle, etc. [15]. The train measurements allow the sleeper voids identification from the nonlinear track stiffness; however, the system has many technical limitations such as the low train velocity and accuracy. The frequent application of the systems is limited with high costs resulting from the necessity of the special measurement trains. The track-side sensor-based measurement systems for the track stiffness identification in the transition zones are presented in Ref. [16]. Three different measurement systems were used for the dynamic deflection measurements of 18 sleepers: video recording, laser-based, and geophone. The measurements were used for the estimation of the subgrade linear stiffness based on the beam on elastic foundation theory. Kaewunruen et al. [17] have developed a curvature-based damage detection method for the identification of the ballast voids under railway track sleepers. This method is declared to be easily deployed in the field by using fiber Bragg grating strain sensors to measure strains for curvature analysis. A similar approach is proposed in Refs. [18, 19], where the quantification of the ballast support condition is proposed on the basis of the pressure distribution identification. The approach uses the measurement of bending moment profile across the concrete sleeper for the back-calculation of the ballast support condition with the use of an optimization algorithm. The ballast pressure index is also proposed to quantify the variation of ballast pressure beneath the sleepers. A method 
for identification of the damaged ballast supports by using track-side vertical acceleration measurement is proposed in Ref. [20]. The method is based on a dynamic model of the track as an Euler beam on the discrete supports. The chance of the periodical natural frequencies in the interaction system is considered as an indicator of the damaged support. An application of onboard inertial measurements from in-service trains for the identification of the sleeper support conditions is presented in [21]. The detection algorithm was developed by a multi-resolution analysis and state machine design methodology. The multi-source data analysis is proposed to ensure the rapid monitoring of the entire rail network. The railway infrastructure condition monitoring based on data from distributed acoustic sensing and the fractal analysis of the vertical track geometry is proposed in $[22,23]$. The approach can distinguish whether irregularities within track geometry are caused by the interaction between sleepers and ballast (hanging sleeper), ballast breakdown and fouling, respectively, or weak subsoil condition. Boehm and Weiss [24] presented a concept of track-side monitoring to avoid control in the switch zone of a turnout. The monitoring is based on the continuous acceleration measurements of a sleeper. The studies $[25,26]$ demonstrate a method for track-side assessment of sleeper support conditions. The proposed method is based on the sampling of the microtremor on sleepers and interpretation of obtained data. Pang et al. [27] presented a non-contact and nondestructive method for estimation of the flexural behavior of the concrete sleepers under various support conditions. The method is based on laser speckle imaging. This method was successfully implemented for strain sensing in railway applications and tested in laboratory conditions. An approach for track support condition monitoring using inertial measurements is presented in Ref. [28]. The approach suggests identification of sleeper deflection, track modulus, and atrest position. Reference [29] indicates the importance of taking into account the dynamic properties of railway track components in testing and design.

The above literature analysis shows a wide range of studies on sleeper void influence on the dynamic track behavior and track geometry. However, most of studies are based on theoretical research with low experimental substantiation. A few experimental investigations on sleeper support monitoring present some measurement concepts with less practical results of in situ measurements.

The current study presents a systematical approach that contains measurement, modeling, and identification parts. The measurement part presents different measurements for the voided sleepers and the reference track and aims to find the main features of the voided track interaction. The simple modeling part aims to explain the mechanism of the interaction and some aspects that are important for trackside and onboard measurement. The third part is directed on the practical problem of track support diagnostics- the track void parameter identification and quantification.

\section{In situ measurements of rolling stock and track interaction in voided zone}

One of the results of the voided sleepers is ballast breakdown or pulverization that is visible as ballast white spots. The ballast breakdown typically appears in places where the sleeper voids appear in groups of many sleepers together, causing high track deflections and wear of ballast stones. The groups of voided sleepers usually relate to some local disturbances like dipped weld, crossing, subgrade stiffness variation, etc. These places with the different development extent were chosen for the investigation. One of the problem places is shown in Fig. 1.

The track-side measurements were carried out with three different means (Fig. 2): acceleration sensor on the rail foot, LVDT (linear variable differential transformer) sensor between the rail foot and console beam located on the base $1.5 \mathrm{~m}$ out of the rail, and multi-point measurements of sleeper and rail deflections using high-speed imaging. The present study deals with the results of the first two means. The high-speed imaging was used as a cost-effective surrogate tool for the statistical data collection from many problem places. The imaging results will be discussed in further research.

The acceleration measurement is based on B\&K IEPEacceleration sensor of type $4513( \pm 500 \mathrm{~g})$. The sensors with adapter plates were glued on the rail foot. The inductive LVDT sensor is HBM-type W10. The measurement signals were recorded with the sampling rate $2400 \mathrm{~Hz}$ using HBM-Measurement system MGCplus.

All the measurements were carried out synchronously with two measurement toolsets: in the void zone and the reference one that is $8-10 \mathrm{~m}$ outside without sleeper voids. The measurement point is located approximately in the middle part of the visible outside the voided zone. The measurement scheme is explained in Fig. 3.

One aim of the present research is to identify the distinctive features of the dynamic behavior in the voided zone. Therefore, in this work, only the typical measurement results are considered for one problem place. Three cases of the void development extent are considered: small voided zone (case 1), average voided zone (case 2), and big voided zone (case 3 ).

The acceleration measurements for the average voided zone (case 2) and the reference one are demonstrated in Fig. 4. The measurement corresponds to the passenger train RBDe 560 (NPZ Domino 3) with the velocity of $125 \mathrm{~km} / \mathrm{h}$. The maximal accelerations reach $300-500 \mathrm{~m} / \mathrm{s}^{2}$. The main difference between the voided and the reference zone 


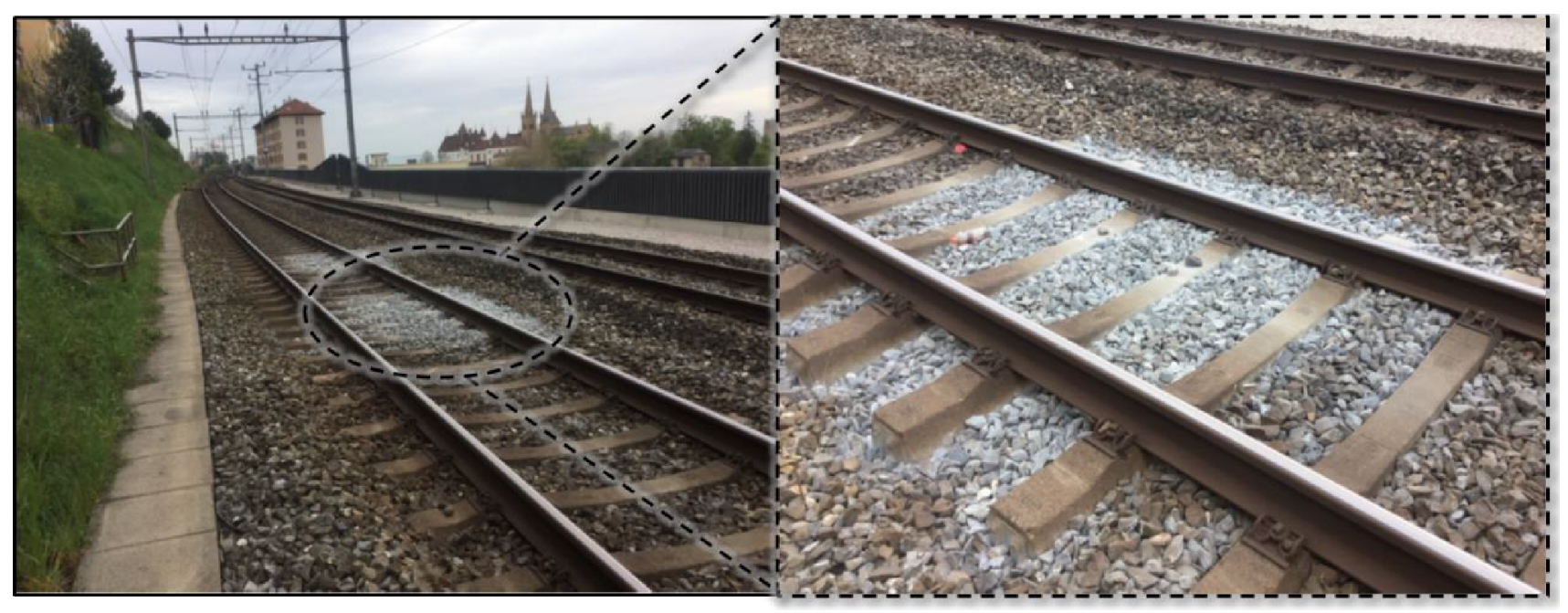

Fig. 1 White spots of ballast breakdown due to voided sleeper

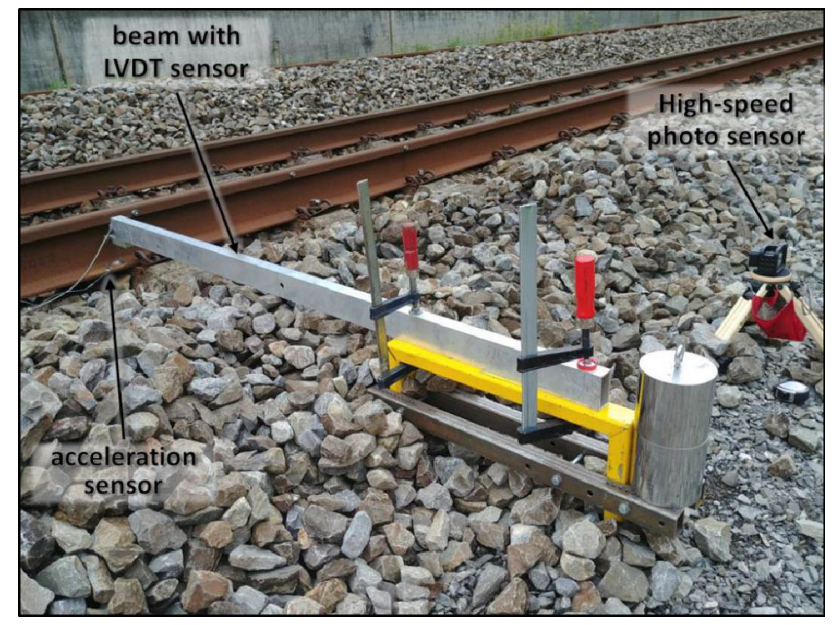

Fig. 2 Experimental setup for rail deflection and acceleration measurement

accelerations is that the accelerations in the voided zone are about $100 \mathrm{~m} / \mathrm{s}^{2}$ lower than in the reference one. The fact can be explained with the lower track stiffness in the voided zone. The low-frequency analysis, as well as the acceleration-based rail deflection result, does not provide significant features due to the low sensitivity of the used sensors.

Whereas the acceleration measurements turn out to be low informative, the simultaneous LVDT measurements show quite a different result (Fig. 5a). The main difference between the voided and reference track is the rail deflection amplitude: The rail maximal negative deflection in the voided zone reaches about $3.6 \mathrm{~mm}$ for the car wheels, whereas the same for the reference case is $0.5 \mathrm{~mm}$. The rail deflections under the locomotive are correspondingly $4.9 \mathrm{~mm}$ and $0.7 \mathrm{~mm}$ for the voided and the reference zones. The additional features of the voided zone are the longer wavelength of the elastic deflection as well as the higher maximal positive deflection of the rail compared to the reference case. However, the most interesting feature of the voided zone is the local disturbance points that are located on the left part of the elastic deflection wave (Fig. 5a) before the maximal negative deflection is reached. The disturbance points appear both for the low and high train velocities. For low axle loadings and high velocities, there is also a sequence of up to three disturbances on the left part of the elastic deflection wave. The unloading parts of the wave have no obvious disturbance points.

The differences in the dynamic behavior of the track in the voided and reference zones are better visible on the rail accelerations (Fig. 5b) that are determined from rail deflections. The figure shows that the local disturbance points of the rail deflection correspond to relatively high impact accelerations while the wheel entries in the voided zone. The rail acceleration in the voided zone reaches $7 \mathrm{~m} /$ $\mathrm{s}^{2}$, while for the reference case, the maximal acceleration points correspond to the maximal deflection and amount to about $2 \mathrm{~m} / \mathrm{s}^{2}$.

The LVDT measurements of rail deflections and the derived accelerations for the smaller voided zone (case 1) are presented in Fig. 6. The loading scheme corresponds to the first part of the passenger train ICE1 with the velocity $110 \mathrm{~km} / \mathrm{h}$. The difference between the maximal deflections of the voided and the reference zones is $1.6-1.8 \mathrm{~mm}$ that is about two times less than for case 2. Different to case 2, the measured rail deflections (Fig. 6a) have no clearly visible disturbance point. Nevertheless, there is a dynamic impact visible on the acceleration diagram (Fig. 6b). The maximal accelerations for case 1 are almost two times lower than for case 2. However, their time positions are differently 


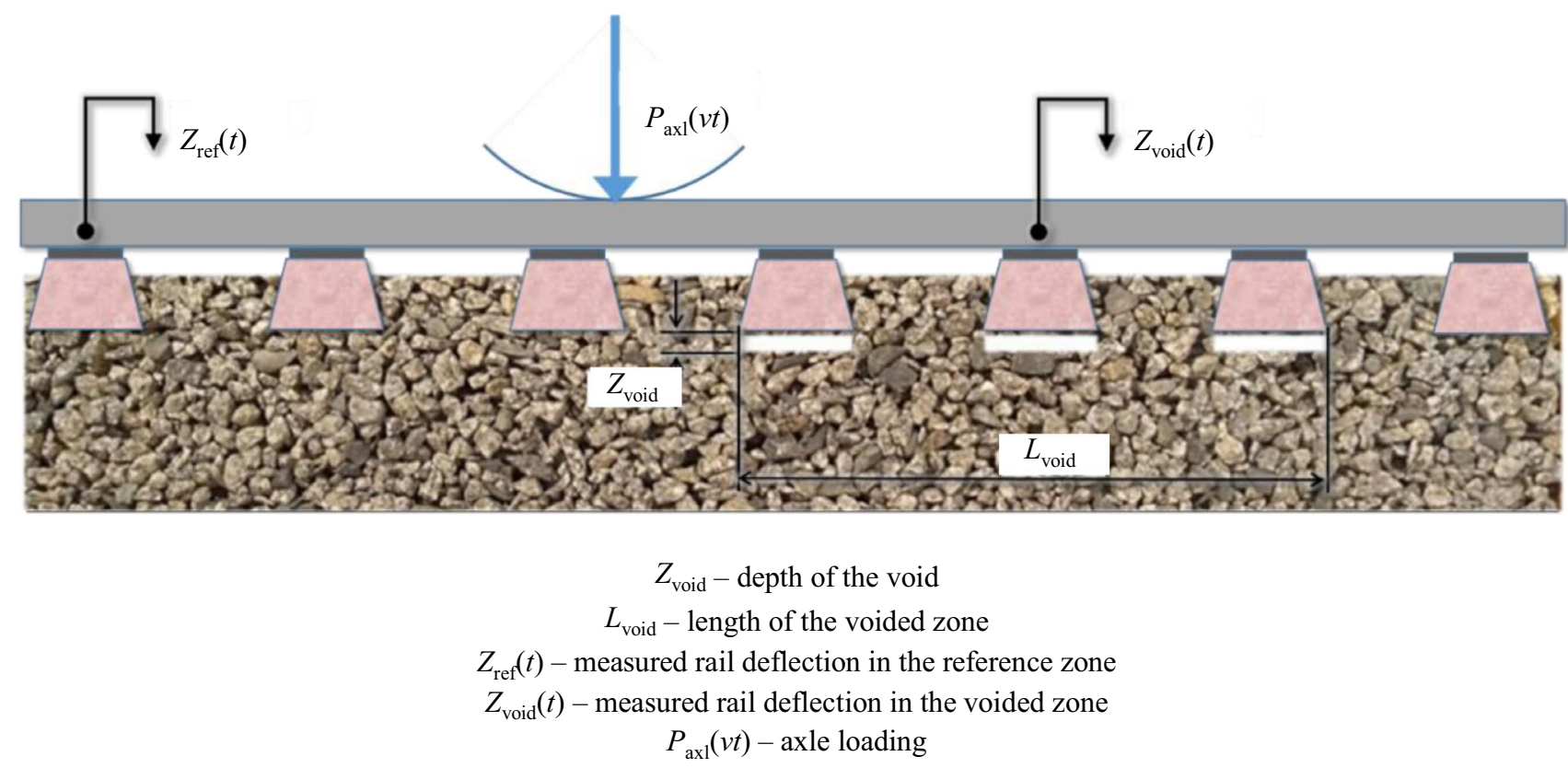

Fig. 3 Measurement of rail deflection in the voided zone and the reference measurements

distributed between the axles. For case 2, the maximal impacts always occurred before the first axle (Fig. 6b).

The measurement result for the big voided zone case 3 (Fig. 7) is quite different as for first two cases. The maximal differential deflections reach $5.1 \mathrm{~mm}$ that is about 1.7 times more than for case 2. However, the dynamic impact with about $25 \mathrm{~m} / \mathrm{s}^{2}$ is up to four times higher than for case 2. Notable is the time position of the impact before the first axle as for case 2 .

Thus, the experimental measurement analysis shows that the voided zones are characterized by an increase in the deflections. The secondary feature is an increased dynamic impact. The dynamic impact can be clearly observed on the rail accelerations. The increase in the rail deflections in the voided zone causes not proportionally quick growth of the accelerations. However, the signal forms and impact time moments are different for the selected three cases of void extent. The general problem of the presented track-side measurements is that they are not directly comparable due to the different conditions of the measurement. First of all, the sensor positions were selected rather arbitrary not over the impact point, which is explained with the observed precession of the maximal acceleration to that of deflection. This means that the observer bias is possible, which can lead to other acceleration results for the different measurement point. It is necessary to study the measurement aspects of the dynamic track interaction in the voided zone by the mathematical modeling.

\section{Mathematical modeling for the measurement aspects of the dynamic track interaction in the voided zone}

The presented results show that only experimental measurement cannot completely explain the dynamic interaction. The aim of the applied modeling is to explain the mechanism of the dynamic behavior of the railway track with sleeper voids and its influence on the track-side measurements.

The model is presented by one Euler-Bernoulli beam on an elastic Winkler foundation (Fig. 8, top). The beam depicts the flexural properties of rails as bending stiffness $E I_{\mathrm{T}}$ and their inertial properties together with fastenings and sleepers mass in the form of meter mass $\bar{m}_{\mathrm{T}}$. The foundation corresponds to the ballast and the subgrade and is presented by viscoelastic underlay with the meter stiffness $\bar{k}_{\mathrm{T}}$ and the meter viscosity $\bar{\eta}_{\mathrm{T}}$. The inertial properties of the ballast and the subgrade are not taken into account. The vehicle is presented by the static loading $F_{0}$ and the unsprung mass $m_{U}$ that is dynamically coupled with the beam.

The model takes into account the voids under the sleeper that are isolated in a group with the parameters: length $l_{\text {void }}$ and the void depth $z_{\text {void }}$ (Figs. 3 and 8, top). The beam foundation properties $\overline{k_{\mathrm{T}}}$ and $\bar{\eta}_{\mathrm{T}}$ depend on the void parameters. The influence of the void depth $z_{\text {void }}$ on the foundation reactive properties is presented in Fig. 8 (bottom) and is described by the following relation: 

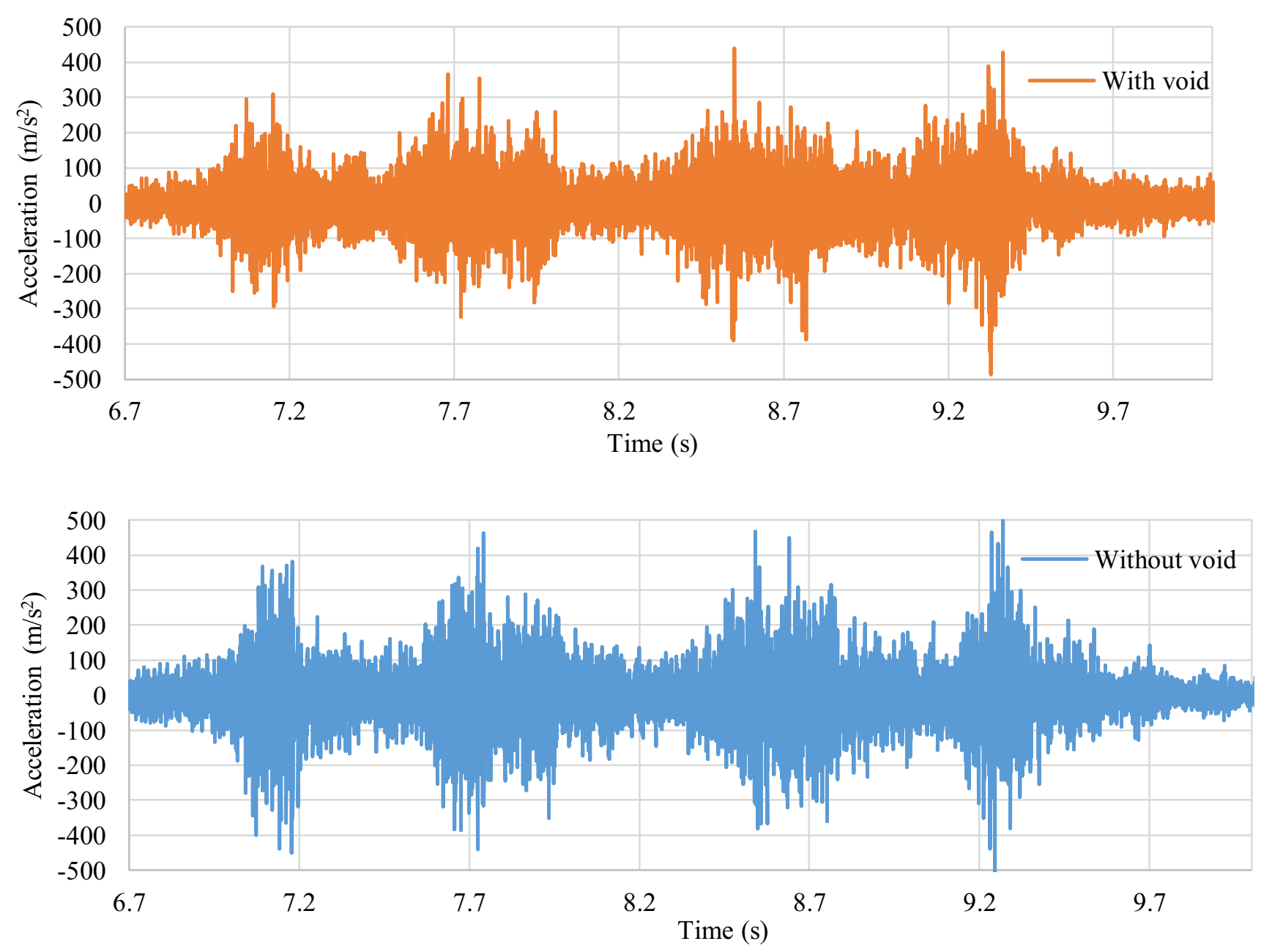

Fig. 4 Measured rail accelerations in the voided zone (case 2) and the reference zone

$F_{\mathrm{b}}=\left\{\begin{array}{r}-\bar{k}_{\mathrm{T}}\left(z_{\mathrm{T}}-z_{\text {void }}\right)-\bar{\eta}_{T} \dot{z_{\mathrm{T}}}, \text { if } z_{T}>z_{\text {void }} \\ 0, \text { if } z_{\mathrm{T}} \leq z_{\text {void }}\end{array}\right.$

The model is described by the following differential equation:

$$
\begin{aligned}
& E I_{\mathrm{T}} \frac{\partial^{4} z(x, t)}{\partial x^{4}}+\bar{m}_{\mathrm{T}} \frac{\partial^{2} z(x, t)}{\partial x^{2}}+\bar{\eta}_{\mathrm{T}} \frac{\partial z(x, t)}{\partial x}+\bar{k}_{\mathrm{T}} z(x, t) \\
& \quad=F_{\mathrm{c}}\left(x_{\mathrm{c}}, t\right),
\end{aligned}
$$

where $F_{\mathrm{c}}\left(x_{\mathrm{c}}, t\right)$ is the wheel and rail interaction force.

The force $F_{\mathrm{c}}$ takes into account the excitation geometry $z_{\mathrm{E}}$ due to geometrical track irregularities and couples the dynamic interaction of the beam and the unsprung mass within the following equation:

$F_{\mathrm{c}}\left(x_{\mathrm{c}}, t\right)=\left(m_{\mathrm{U}}\left(\ddot{z}_{E}\left(x_{\mathrm{c}}\right)-\ddot{z}\left(x_{\mathrm{c}}, t\right)\right)+F_{0}\right) \cdot \delta\left(x_{\mathrm{c}}\right)$,

where the function $\delta\left(x_{\mathrm{c}}\right)$ corresponding to the operation vector $\boldsymbol{\delta}$ of the dimension $n_{x}$ introduces the wheel interaction with one-beam element located at the contact point $x_{\mathrm{c}}$ depending on the wheel velocity $v$ and time: $x_{\mathrm{c}}=x_{0}+v t$.

The elements of the operation vector $\delta$ assume the two states one or zero, depending on whether or not the contact force interacts with the beam element:

$\begin{aligned} \delta_{j} & =1 \text { for } j \Delta L=x_{\mathrm{c}} \\ \delta_{j} & =0 \text { for } j \Delta L \neq x_{c} .\end{aligned}$

The resulting equation of coupled dynamic interaction of the unsprung mass and the beam with voids is presented with the matrix equation:

$\boldsymbol{M}_{\mathrm{T}} \ddot{z}_{\mathrm{T}}+\boldsymbol{H}_{\mathrm{T}}\left(\boldsymbol{z}_{\mathrm{T}}\right) \dot{z}_{\mathrm{T}}+\boldsymbol{K}_{\mathrm{T}}\left(\boldsymbol{z}_{\mathrm{T}}\right) \boldsymbol{z}_{\mathrm{T}}=m_{\mathrm{U}} \ddot{\boldsymbol{z}}_{\mathrm{T}} \boldsymbol{\delta}+F_{0} \boldsymbol{\delta}$.

where $\boldsymbol{M}_{\mathrm{T}}, \boldsymbol{H}_{\mathrm{T}}$, and $\boldsymbol{K}_{\mathrm{T}}$ are the mass, damping, and stiffness matrices of the continuous beam and foundation of the length $L$ that are discretized into $j=1,2, \ldots, n_{x}$ elements of length $\Delta L ; z_{\mathrm{T}}$ is the vertical displacement vector of the elements.

The detailed description of the ordinary differential equation (ODE) using the finite difference method for the linear one-beam model is presented in [30]. 


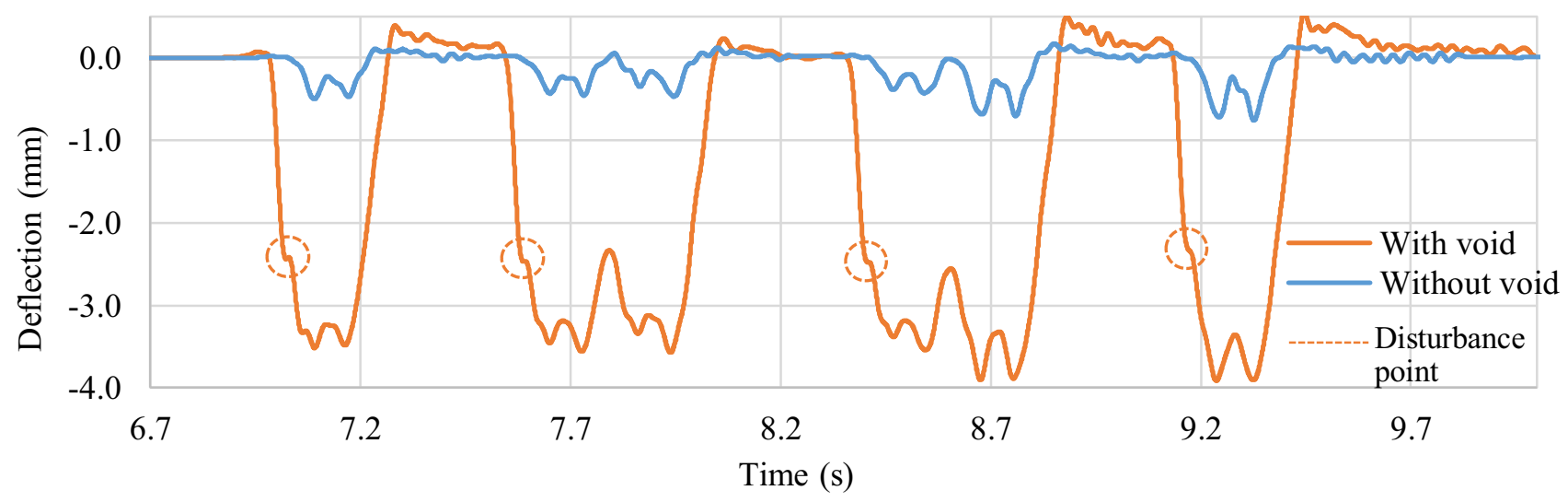

a

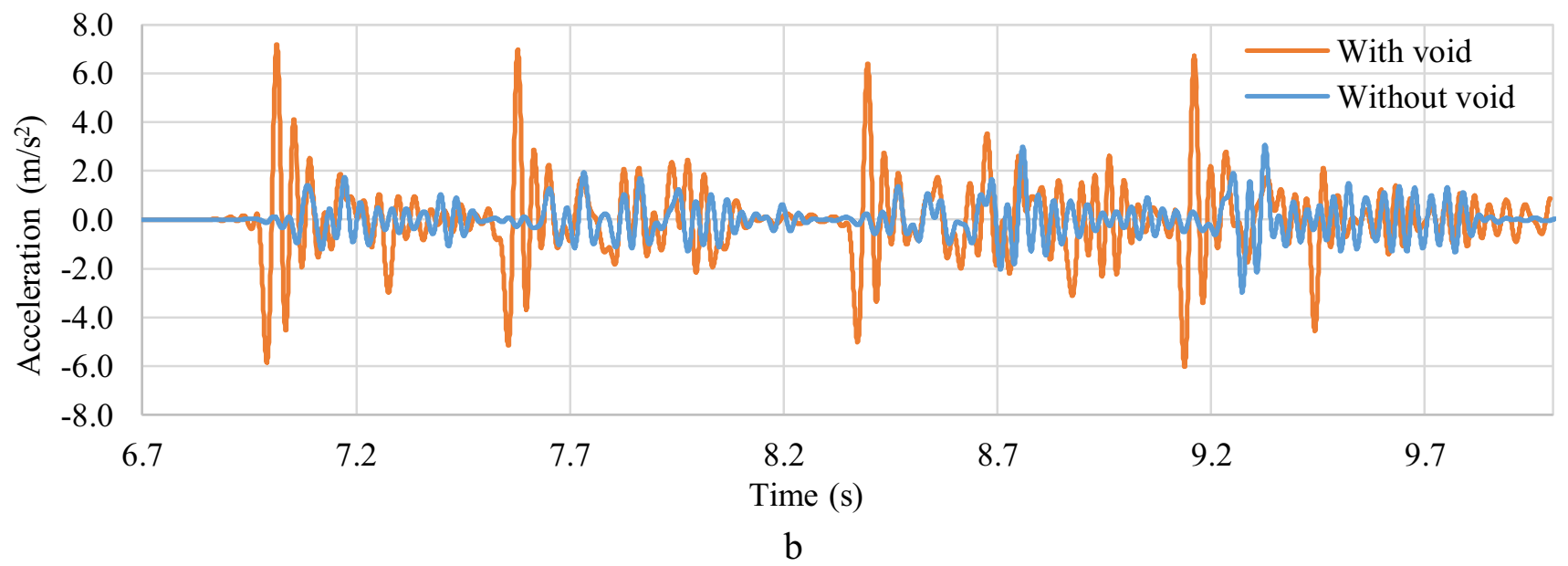

Fig. 5 Measured rail deflections (a) and accelerations derived from LVDT (b) in the voided zone (case 2) and the reference zone

The model is used for simulation of the rolling stock and track interaction in the voided zone and the reference case without voids as described in the experimental measurements (Fig. 3). The model parameters in Table 1 are selected so that the simulated results approximately correspond to the measured ones (case 2) for the reference case. The track meter mass assumes the mass of the rail UIC60 together with half sleepers B70 with fastenings. Track foundation meter stiffness $\overline{k_{\mathrm{T}}}$ is chosen to provide close to the measured rail deflections for the reference case.

The void parameters $z_{\text {void }}=3 \mathrm{~mm}$ over the length $2 \mathrm{~m}$. The voided zone is located under the mean part of the beam model of the length $20 \mathrm{~m}$. The simulation results for the one wheel with velocity $100 \mathrm{~km} / \mathrm{h}$ are presented as the track deflection and accelerations.

Figure 9a shows the simulated measurements of rail deflections in the different track sections relative to the voided zone as well as wheel trajectory in the track axis coordinate system. The same simulation is presented for the track without voids (Fig. 9b). This diagram shows the typical curves of the beam on the elastic foundation that have their maxima in the measurement sections of the track. The wheel trajectory (Fig. 9b) is the horizontal line and corresponds to the maximal deflection points in the track sections.

Unlike the reference case, the simulation for the voided track demonstrates quite different deflections. The simulated deflection measurement curves are different for the track sections with different positions over the void zone. The deflections in the left half of the voided zone in the sections $9.0 \mathrm{~m}$ and $9.4 \mathrm{~m}$ have their maximal value not under the wheel loading, but there the wheel position has the longitudinal track coordinate $9.8 \mathrm{~m}$.

The curves of track deflections measurements in the right half of the voided zone have their maxima under the wheel loading. However, all the curves have additionally local minimum or disturbance point that is located in the track coordinate $9.8 \mathrm{~m}$. Here, the modeled track deflections in Fig. 9a show the typically measured deflection curves in Fig. 5, where the local disturbances appear during the wheel entry into the voided zone. 

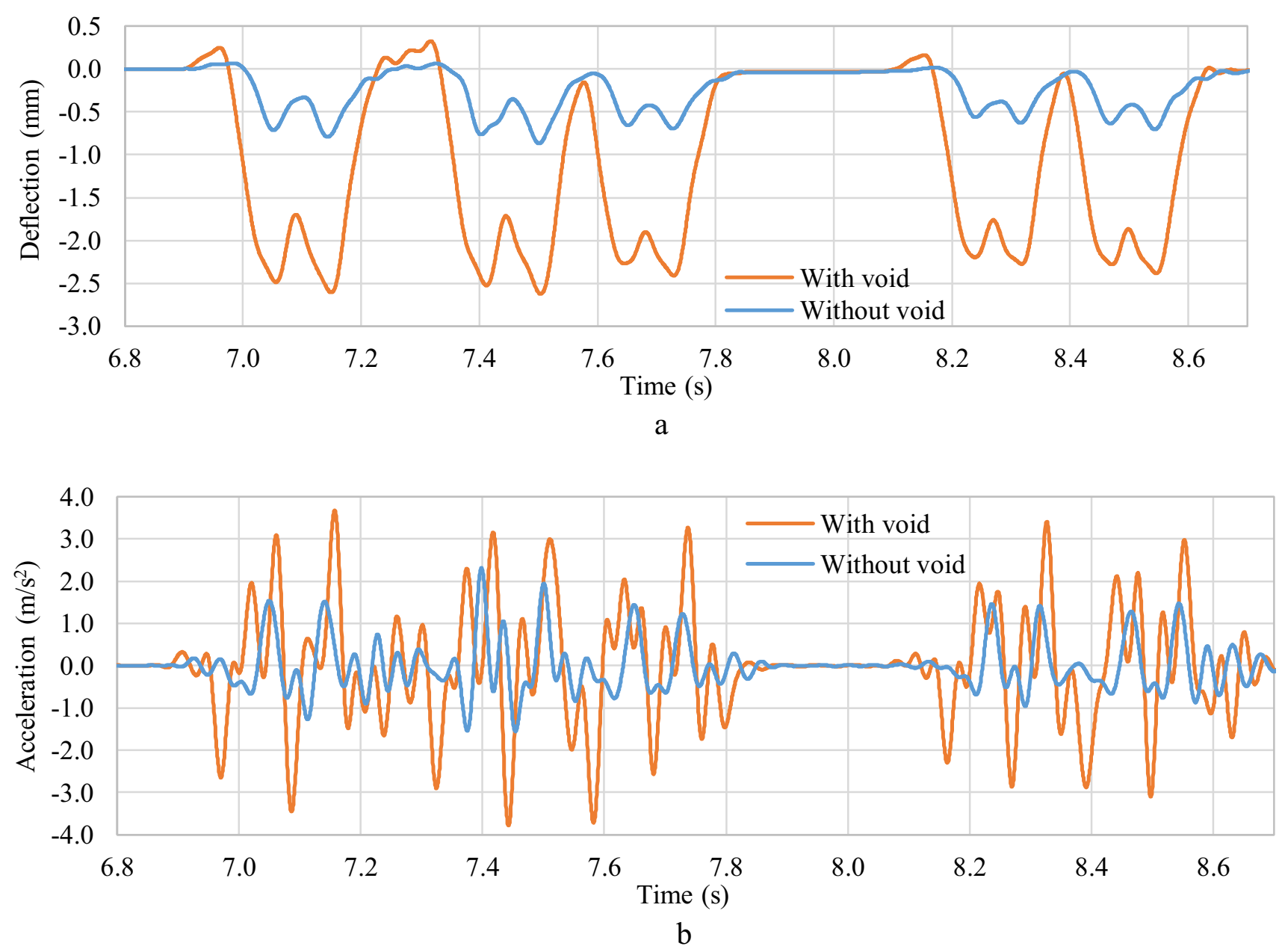

Fig. 6 Measured rail deflections (a) and accelerations derived from LVDT (b) in the voided zone (case 1) and the reference zone

The wheel trajectory line (Fig. 9a) explains the reasons for the behavior. The local disturbance point in the track coordinate $9.8 \mathrm{~m}$ corresponds to the maximal wheel deflection after the entry in the voided zone. After the first maximum of the wheel deflection follows the second local one.

Both the length of the wheel trajectory disturbance and those of the simulated track deflection measurements are influenced by the length of the voided zone. The wheel trajectory disturbance has a length of about $3.5 \mathrm{~m}$, and the track section deflection lines have the lengths about $4.5-5 \mathrm{~m}$, whereas the modeled voided zone is $2 \mathrm{~m}$ long. The negative deflection waves for the track without void (Fig. 9b) that corresponds to the reference case have the lengths about $3.0 \mathrm{~m}$. Thus, the comparison of the track deflection lines for the voided zone and out of the voided zone potentially can be used for track-side and onboard identification of the voided zone sizes.

The analysis of the simulated rail and wheel accelerations (Fig. 10) provides additional explanation about the dynamic behavior of track in the voided zone. This figure presents the wheel and the track accelerations for the same track section along the voided zone as in Fig. 9. The maximal accelerations of the track without voids amount to $2.1 \mathrm{~m} / \mathrm{s}^{2}$ that appear during the phase of the wheel passing the track sections (Fig. 10b). The process of track acceleration in the track sections over the voided zone (Fig. 10a) is quite different. The maximal accelerations for all considered track sections are reached in one point along the track with the coordinate $9.8 \mathrm{~m}$. This maximal acceleration point is explained with the dynamic excitation due to closing the void under the sleeper and the impact of the sleeper to the ballast layer. Except the first impact, the track acceleration lines show the latter following the second and the third maxima that correspond to the dynamic interaction due to the flexible beam line and the dynamic wheel trajectory during run-out from the voided zone.

Comparing the measured and simulated accelerations for voided zone shows similarities and also significant differences. The maximal accelerations amount to about 


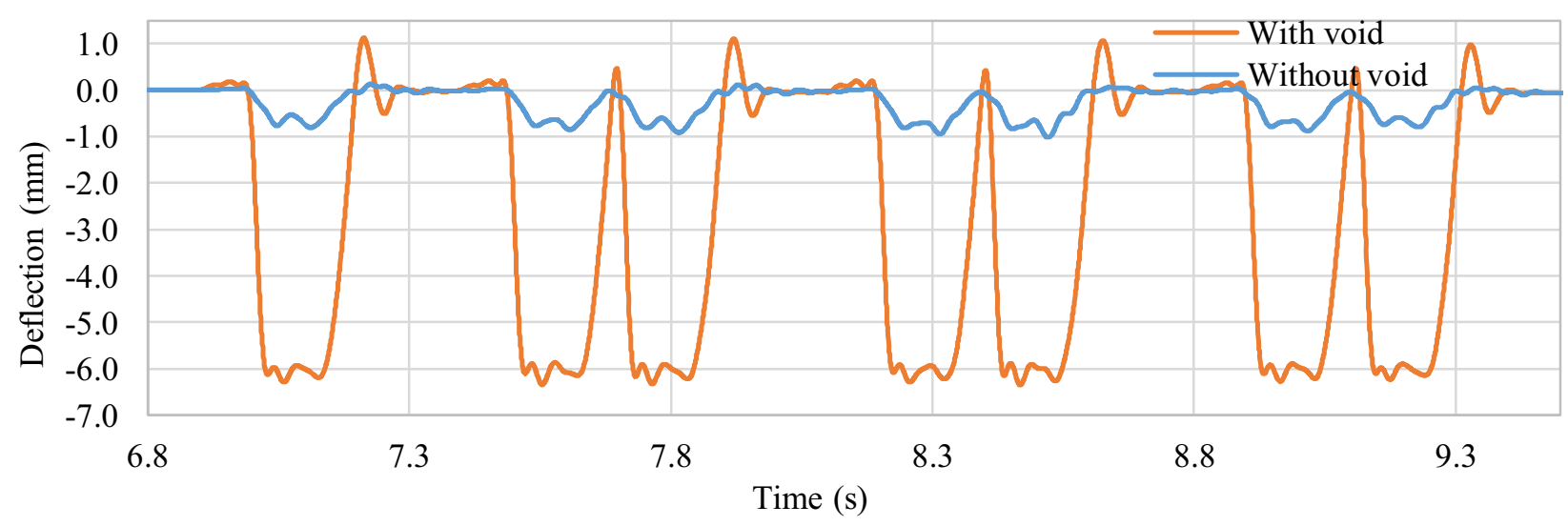

a

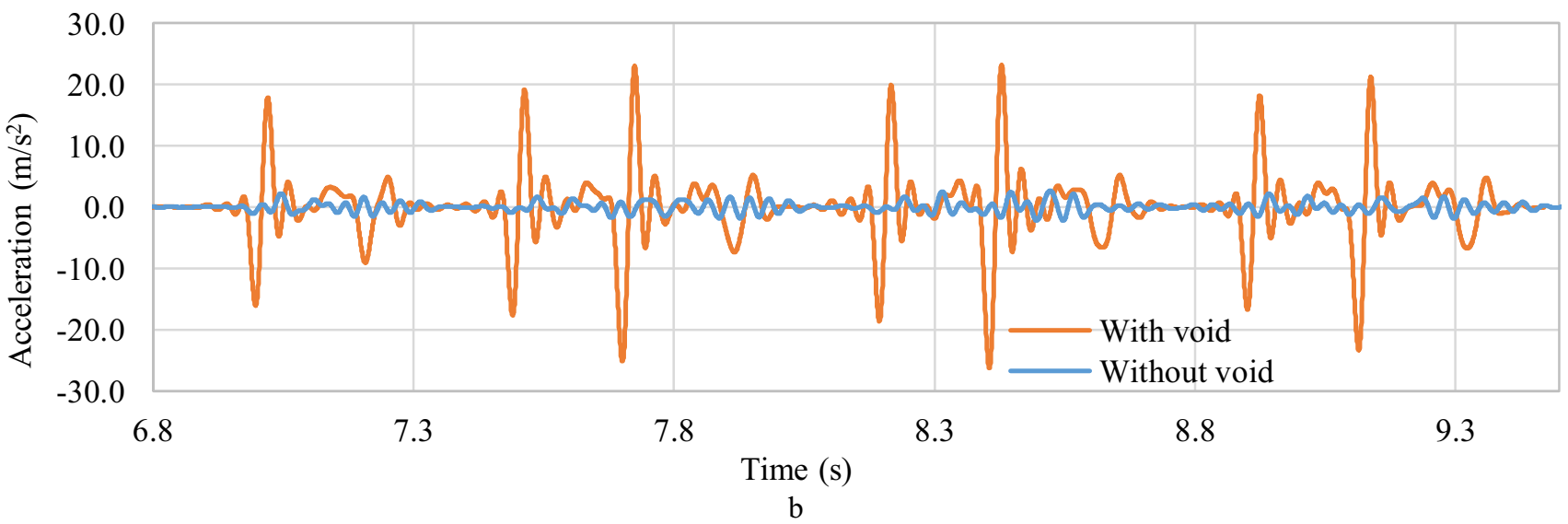

Fig. 7 Measured rail deflections (a) and accelerations derived from LVDT (b) in the voided zone (case 3) and the reference zone

Table 1 Parameters of the dynamic model

\begin{tabular}{ll}
\hline Parameter & Value \\
\hline Static wheel force & $F_{0}=100 \mathrm{kN}$ \\
Unsprung wheel mass & $m_{\mathrm{U}}=1000 \mathrm{~kg}$ \\
Track meter mass & $\bar{m}_{\mathrm{T}}=330 \mathrm{~kg} / \mathrm{m}$ \\
Bending stiffness & $E I_{\mathrm{T}}=6.4 \mathrm{MN} \cdot \mathrm{m}^{2}$ \\
Foundation coefficient & $\bar{k}_{\mathrm{T}}=120 \mathrm{MN} / \mathrm{m}^{2}$ \\
Track damping & $\bar{\eta}_{\mathrm{T}}=0.25 \mathrm{MN} \cdot \mathrm{s} / \mathrm{m}^{2}$ \\
\hline
\end{tabular}

4-16 $\mathrm{m} / \mathrm{s}^{2}$ depending on the distance from the first impact point to the measurement section. Thus, the acceleration simulation results correspond to experimentally estimated accelerations about $7 \mathrm{~m} / \mathrm{s}^{2}$ (Fig. 5b) taking into account that the measurement sensor position has the distance 0.4-0.5 $\mathrm{m}$ to the first impact point. Thus, similar to the experimental results, the simulated maximal acceleration occurs before the maximal rail deflection is reached.
Different to the simulated deflection, the form of the simulated acceleration over time is less similar to the measured one. The process of the measured acceleration shows more oscillations both for the void and reference cases. The similar frequency about $28 \mathrm{~Hz}$ for both cases could be explained with the frequency of track grid due to fastenings. The one-beam model cannot take into account these oscillations.

Comparison of the maximum positions of the first and the second impacts in the acceleration and deflection diagrams can be used for the track-side identification of the void beginning and end coordinates relatively to the measurement track section.

\section{Parameters identification of track with voided support}

The goal of the section is to develop a simple practical method for track voids parameters quantification. On the one side, the conventional visual inspection methods provide very coarse estimation of the void visible length and 


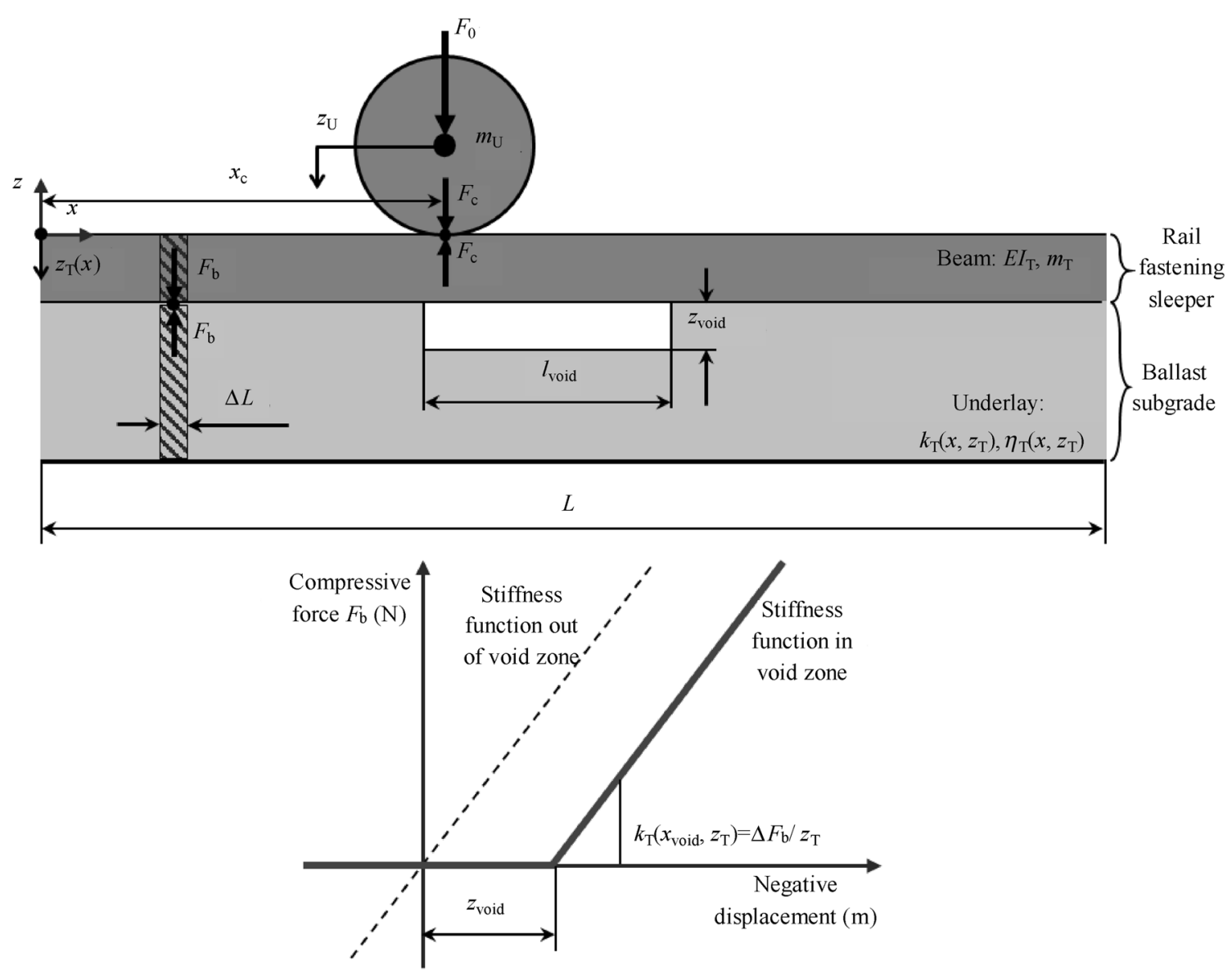

Fig. 8 Beam model of track and wheel interaction

its severity in the form of several levels of grading. The presented track-side measurements compared with the reference case provide additional information about the void depth. Moreover, the calibration of the presented onebeam dynamic model would potentially bring new parameters like foundation stiffness and damping distribution along the track, void depth distribution, etc. The model calibration is based on the multi-dimensional parameters search with fitting the simulation results to the experimental ones. However, such approach is quite timeexpensive and can lead to the parameter uncertainty, which is not suitable for the practical application. Therefore, a simplified approach is proposed, taking into account the analytical equation of the rail flexible line on elastic foundation. Therefore, the dynamic behavior of the track is neglected.

The approach allows the identification of the dynamic loadings and the local track stiffness in the voided zone. The similar approaches are presented in [31,32]. The void size quantification of the track stiffness can provide the information about the reasons of the void appearance. The vertical rail deflections on elastic foundation under point loading are described by Eqs. 7-9:

$z(x)=\frac{a}{2 s_{z} L} \eta(x) F_{z}=\hat{z} \eta(x)$

where $a$ denotes the distance between sleeper axles along the track, $F_{z}$ the vertical loading of the wheel on the rail, $s_{z}$ the vertical foundation coefficient of rail sleeper, and $L$ the characteristic length that is determined by

$L=\sqrt[4]{\frac{4 E I}{s_{z}}}$

$E I$ is the bending stiffness of rail; $\eta(x)$ the shape function that determines the elastic line distribution along the rail, which is determined by

$\eta(x)=\mathrm{e}^{-\left|\frac{x-x_{\mathrm{F}}}{L}\right|}\left(\cos \left|\frac{x-x_{\mathrm{F}}}{L}\right|+\sin \left|\frac{x-x_{\mathrm{F}}}{L}\right|\right) ;$

$x_{\mathrm{F}}$ is the relative coordinates of the elastic line to the loading point.

The real rail support has nonlinear elastic properties that are expressed with the initial settlements $z_{0}$. The 

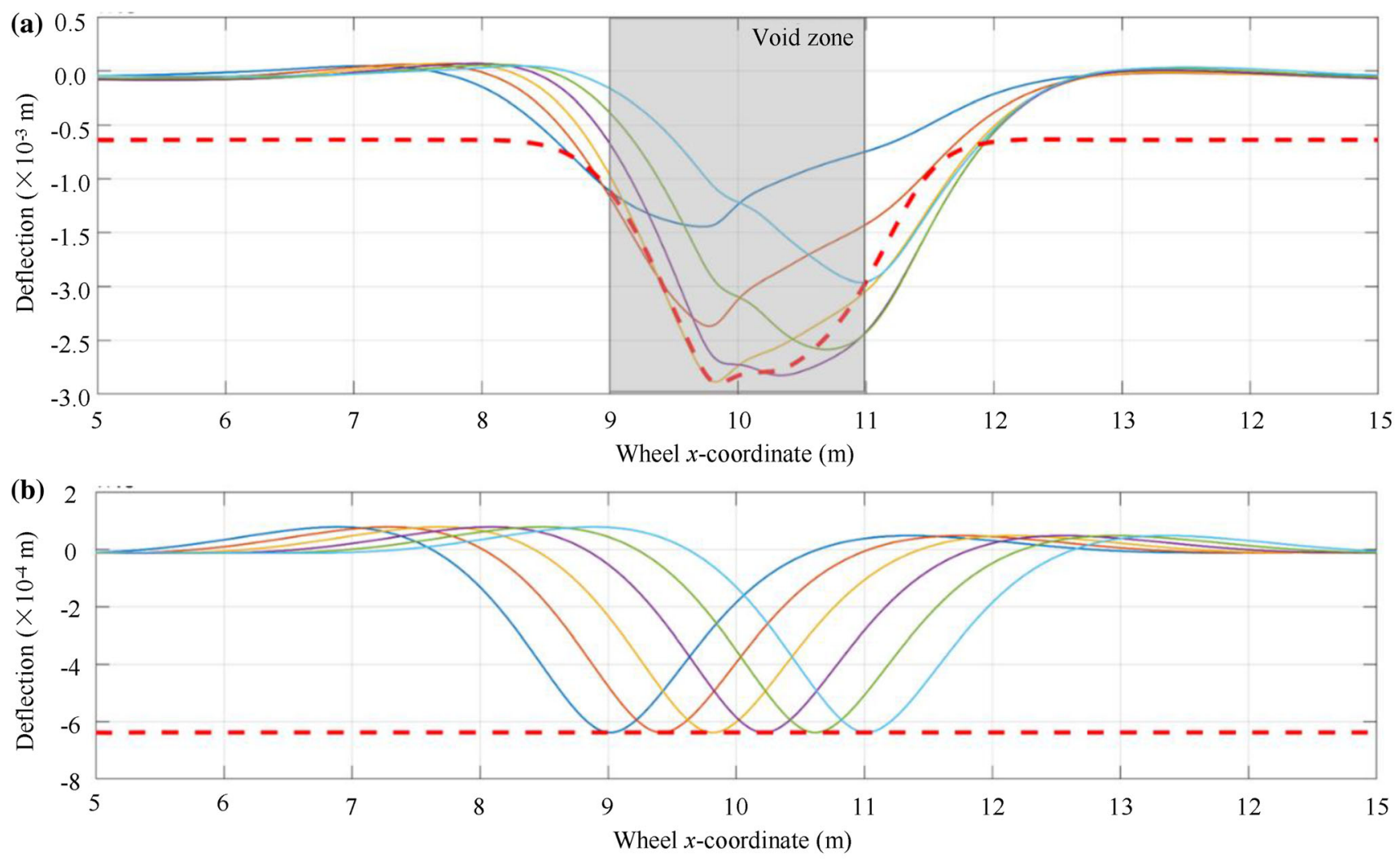

— Track $9.0 \mathrm{~m}$ - Track $9.4 \mathrm{~m}$ - Track $9.8 \mathrm{~m}$ - Track $10.2 \mathrm{~m}$ - Track $10.6 \mathrm{~m}$ - Track $11.0 \mathrm{~m}$ - - Wheel

Fig. 9 Simulated rail deflections and wheel trajectory in the voided zone (a) and the zone without voids (b)

settlements are related to material consolidation and voids between sleeper and ballast. The identification of voided track parameters is based on optimization approach. Track dynamic loading $F_{z}$, track elastic properties $L$, and the initial settlements $z_{\text {void }}$ are determined using the track-side measured rail deflections $z_{\mathrm{m}}$ and the minimization of Eq. (10):

$\min _{F_{z, i}, L, z_{\text {void }}} \sum_{j=1}^{m}\left[-z_{\mathrm{m}}\left(x_{j}\right)+z_{\mathrm{void}}+\sum_{i=1}^{n} \hat{z}\left(F_{z, i}, L\right) \eta_{i}\left(x_{j}\right)\right]^{2}$,

where $m$ is the number of measurement point, and $n$ the number of train axle loadings.

The optimization takes into account the train type known before and the axle distance for the identification of trail velocity. The measurement points for the model fitting are limited to the elastic line length around the loading points. The identification results of axle loadings and the local track stiffness for the both rails are presented in Fig. 11. Two loading types from the deflection measurements case 2 (Fig. 5) are analyzed: car and the locomotive. The results of the model fitting to the rail deflection measurements in the reference track are presented in Fig. 11a, b. The identified axle loadings for the car are in the range of $95-134 \mathrm{kN}$. Therefore, the front axles of the bogies are more loaded than the rear ones that indicate the possible acceleration of the train. The identified axle loadings for the locomotive are $204 \mathrm{kN}$ and $215 \mathrm{kN}$, respectively. The difference between the locally fitted elastic line and the measured global deflections is interpreted as the initial settlements or void depth $z_{\text {void }}$. The reference track shows some low initial settlements $0.06-0.1 \mathrm{~mm}$ that are related to the structural consolidation nonlinearity under the wheel loading. The identified local track stiffness for the whole track is $153 \mathrm{kN} / \mathrm{mm}$ for the car and $146 \mathrm{kN} / \mathrm{mm}$ for the locomotive.

The analysis of the model fitting for the voided track is presented in Fig. 11c, d. The identified axle loadings are up to $17 \%$ higher than for the reference case. That is explained by the additional track irregularity due to differential settlements in the voided zone. The void depth $z_{\text {void }}$ is $3.06 \mathrm{~mm}$. The identified track stiffness is significantly lower than for the reference case and amounts to $136 \mathrm{kN} /$ $\mathrm{mm}$ for the car and $127 \mathrm{kN} / \mathrm{mm}$ for the locomotive. Thus, the voided zone has significantly lower local stiffness than the reference one that can provide evidence to the subgrade inhomogeneity and can be one of the reasons of the void 


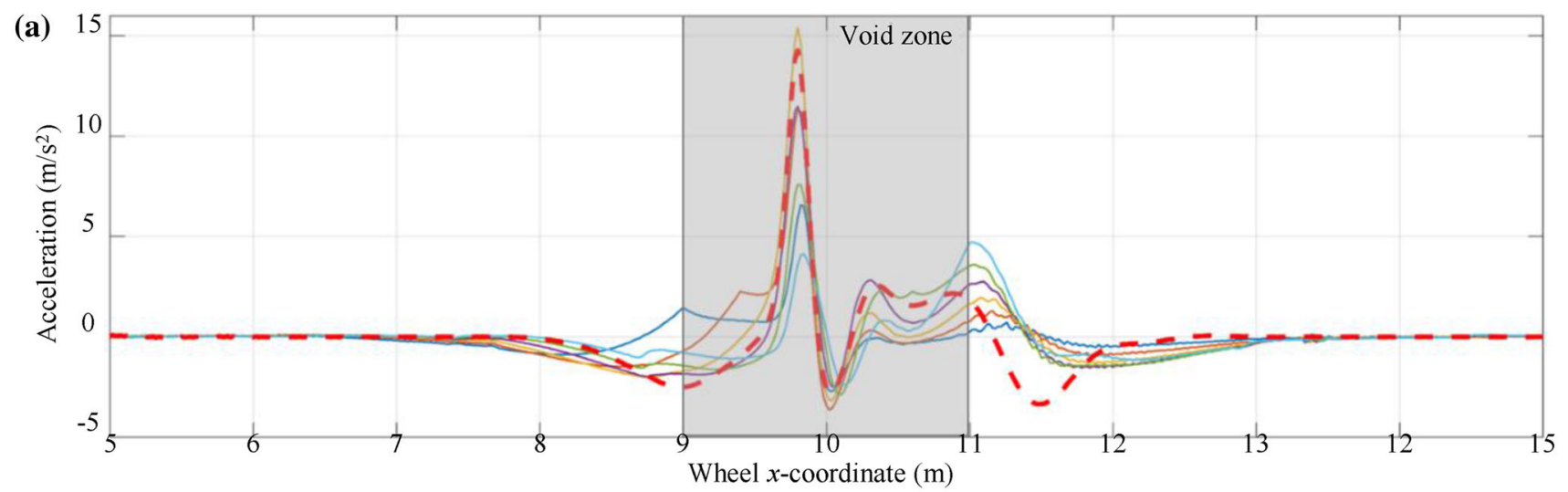

(b) 2.5

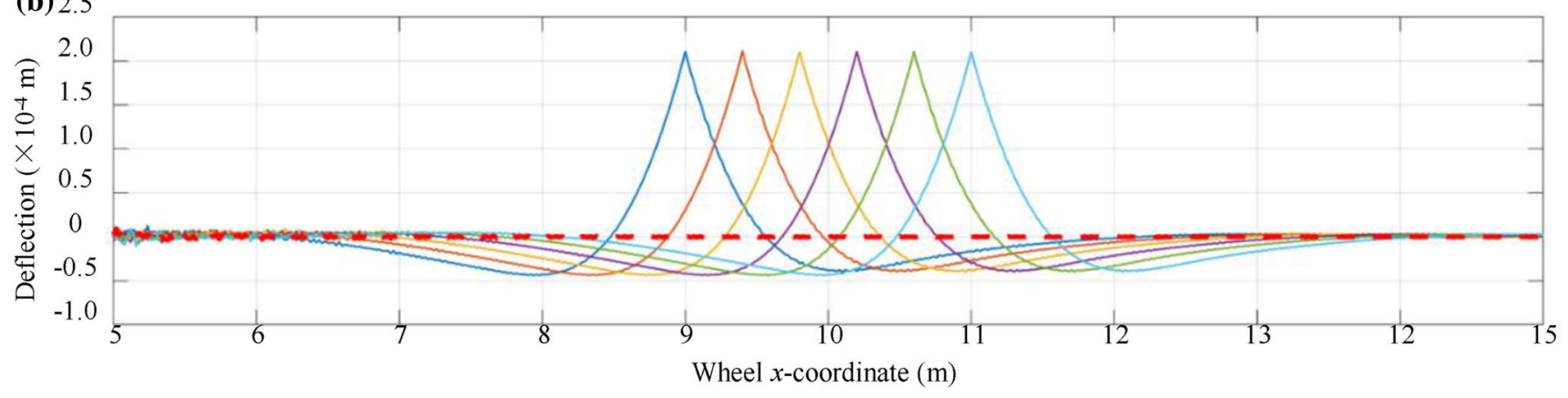

Track $9.0 \mathrm{~m}$ Track $9.4 \mathrm{~m}$

Track $9.8 \mathrm{~m}$ Track $10.2 \mathrm{~m}$ Track $10.6 \mathrm{~m}$ Track $11.0 \mathrm{~m}$ - - Wheel

Fig. 10 Simulated rail and wheel accelerations in the voided zone (a) and the zone without voids (b)

initiation and development. The stiffness identified with the locomotive loading should be considered as more informative since it supposes the fuller closure of the voids under the sleeper.

The identification of void length can be approximately determined from the comparison of the wave lengths between the fitted reference and the voided case that results in the length of $2.5-3.0 \mathrm{~m}$.

\section{Discussion}

The previous literature overview shows that despite of many studies on the void sleeper development, voided track modeling, and measurement concepts, there are few experimental results that explain the dynamic behavior of the voided track with many voided sleepers as a group.

The measurements of three different means show their advantages and shortcomings. The failed interpretation of the acceleration measurements is explained with over dimensioned sensor range and therefore low sensitivity. The sensitivity could be significantly increased by using the low range acceleration sensor together with sensor location transition from rail to sleeper. The one-point LVDT measurements can detect the dynamic impact, but its value is also influenced by measurement point position.
Therefore, the void diagnostics would require the multipoint measurements. The high-speed imaging would be a simple and cost-effective alternative for the multi-point LVDT measurement. The results of high-speed imaging will be presented in the further studies.

The measurements analysis for the voided and the reference track has shown that the behavior of the voided track has many features that can be potentially used for the track-side diagnostics. Except of the differential settlement, the additional feature can be the dynamic impact due to the sleeper void closure during wheel entry in the void zone. However, the impact acceleration process and their maxima locations are quite different for the considered three cases of void development. The accelerations are subjected to the influence of many factors and first of all the LVDT sensor position along the track. The estimation of the factor is carried out using the presented mathematical modeling.

The experimental results are explained with the help of relatively simple simulation of the single beam on the continuous viscoelastic foundation with void zone. The model shows that the measured rail deflections and accelerations depend on the measurement point position relatively to the impact point. The simulation model shows that the acceleration in the impact point location can be more than two times more than the measured maximal $7 \mathrm{~m} / \mathrm{s}^{2}$. Moreover, the accelerations on the contact between the 


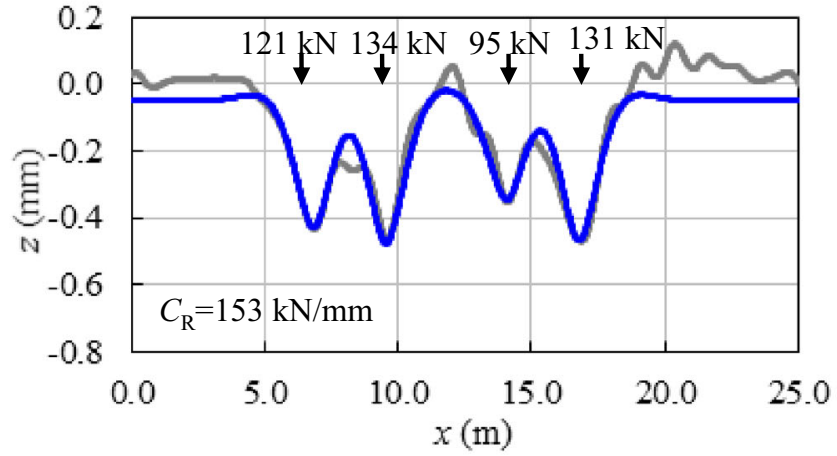

(a)

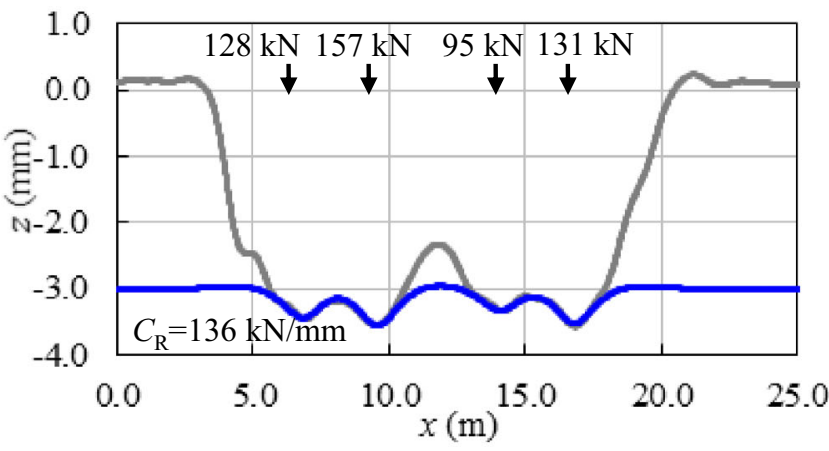

(c)

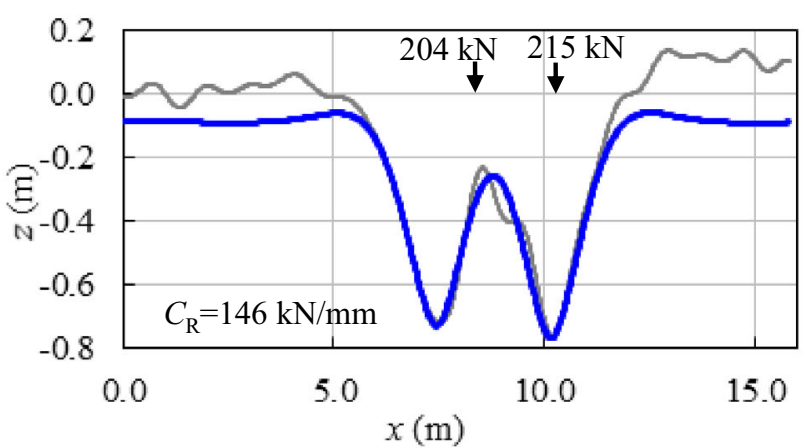

(b)

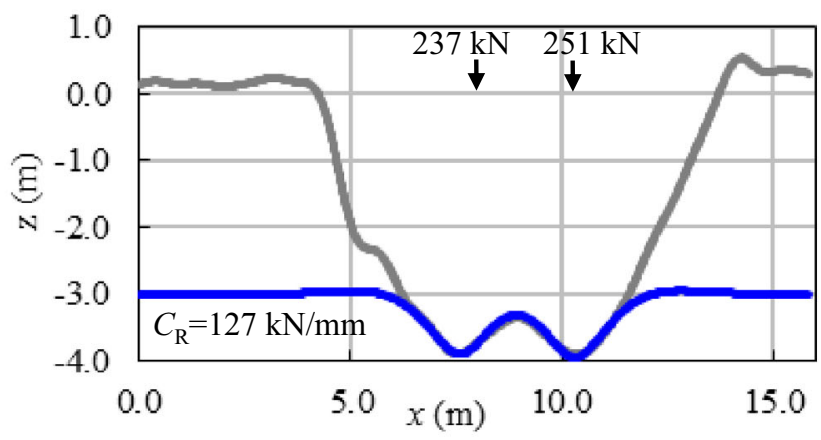

(d)

- Measurement

Model

Fig. 11 Identification of axle loadings and the local track stiffness in the voided zone $(\mathbf{a}, \mathbf{b})$ and the reference zone without voids $(\mathbf{c}, \mathbf{d})$, for the passenger car $(\mathbf{a}, \mathbf{c})$ and the locomotive $(\mathbf{b}, \mathbf{d})$

ballast and the sleeper during the impact can be even higher. Thus, the dynamic behavior in the voided zones makes the conditions for the accelerated growth of the zones. The long-term behavior of the zones is the subject of the further theoretical and experimental research. The proposed one-beam model generally explains the dynamic behavior of the voided track but is oversimplified and does not involve the dynamics of the ballast layer, partially supported sleepers, multiple vehicle masses, etc. The analysis of wheel accelerations shows the similar acceleration process for the track sections with the position in the first impact point. This indicates the possibility of using the cost-effective onboard measurements instead of track-side ones for the purpose of recent void identification.

Another feature of the voided zone, except for the differential settlement and the dynamic impact, could be the local stiffness considered in the proposed identification method. The method for void parameters identification and quantification is based on an assumption that the local elastic wave near the rail loading points is close to the beam on the elastic foundation. This allows simple estimation of the void depth, wheel loadings, and the track local stiffness. The identified stiffness parameter in the voided zone shows significantly lower value than in the reference one, which can explain the void generation. The voided zone length can be determined by comparing the measured wavelengths. However, the proposed method does not take into account the features of dynamic impact and has a bias of the measurement point location. It should be noted that the proposed identification approach does not take into account the geometrical track irregularity. However, its influence on the dynamic axle loading can be considered without separation from other factors.

\section{Conclusions}

1) The experimental measurement analysis shows that the voided zones are characterized by a dynamic impact that appear due to the closure of the voids under the sleeper during the wheel entry in the voided zone. 
2) The impact position relatively to the position of maximal rail deflection depends on the sensor along the track.

3) The applied one-beam model on the elastic foundation explains the mechanism of the interaction and its influence on the track-side and onboard measurement patterns.

4) The modeling shows that the measured impact acceleration could be more than two times higher if the measurement sensor could be located over previously unknown impact point.

5) The multi-point measurements using high-speed imaging or other methods are necessary for void diagnostics.

6) The proposed practical method for the voided track parameter estimation provides the feature of local track stiffness that is considered as the possible reason of the void initiation and development.

Acknowledgements The authors acknowledge the support of Swiss Federal Railways with the experimental measurements.

Open Access This article is licensed under a Creative Commons Attribution 4.0 International License, which permits use, sharing, adaptation, distribution and reproduction in any medium or format, as long as you give appropriate credit to the original author(s) and the source, provide a link to the Creative Commons licence, and indicate if changes were made. The images or other third party material in this article are included in the article's Creative Commons licence, unless indicated otherwise in a credit line to the material. If material is not included in the article's Creative Commons licence and your intended use is not permitted by statutory regulation or exceeds the permitted use, you will need to obtain permission directly from the copyright holder. To view a copy of this licence, visit http://creativecommons. org/licenses/by/4.0/.

\section{References}

1. Lichtberger B (2005) Track compendium: formation, permanent way, maintenance, economics. Eurail Press, Hamburg

2. Fendrich L, Fengler W (2013) Field manual railway infrastructure. Springer, Berlin (in German)

3. Holtzendorff K (2003) Investigation of the settlement behaviour of railway ballast and the void forming on railway tracks, Dissertation, Technische Universität Berlin (in German)

4. Baessler M, Ruecker W (2003) Track settlement due to cyclic loading with low minimum pressure and vibrations. In: Popp K, Schiehlen W (eds) System dynamics and long-term behaviour of railway vehicles, track and subgrade. Lecture notes in applied mechanics, vol 6. Springer, Berlin, Heidelberg

5. Lundqvist A, Dahlberg T (2005) Load impact on railway track due to unsupported sleepers. Proc Inst Mech Eng, Part F: J Rail Rapid Transit 219(2):67-77

6. Plenge M, Lammering R (2003) The dynamics of railway track and subgrade with respect to deteriorated sleeper support. In: Popp K, Schiehlen W (eds) System dynamics and long-term behaviour of railway vehicles, track and subgrade. Lecture notes in applied mechanics, vol 6. Springer, Berlin, Heidelberg
7. Kaewunruen S, Remennikov AM (2007) Investigation of free vibrations of voided concrete sleepers in railway track system. Proc Inst Mech Eng Part F J Rail Rapid Transit 221(4):495-507

8. Kaewunruen S (2008) Application of vibration measurements and finite element model updating for structural health monitoring of ballasted railtrack sleepers with voids and pockets. In: Sapri RC (ed) Mechanical vibration: measurement, effects, and control. Nova Science Publishers, New York

9. Evans G, Shahzad F, de Vries E et al (2009) An investigation of sleeper voids using a flexible track model integrated with railway multi-bodydynamics. Proc Inst Mech Eng Part F J Rail Rapid Transit 223(6):597-607

10. Rezaei E, Dahlberg T (2011) Dynamic behaviour of an in situ partially supported concrete railway sleeper. Proc Inst Mech Eng Part F J Rail Rapid Transit 225(5):501-508

11. Zhu J, Ahmed AKW, Rakheja S et al (2010) Development of a vehicle-track model assembly and numerical method for simulation of wheel-rail dynamic interaction due to unsupported sleepers. Veh Sys Dyn 48(12):1535-1552

12. Zhang DW, Zhai WM, Wang KY et al (2015) Investigation on wheel/rail dynamic interaction in heavy-haul railway line with hanging sleepers. In: Proceedings of the 24th symposium of the international association for vehicle system dynamics (IAVSD 2015), Graz, Austria

13. Nielsen JCO, Li X (2018) Railway track geometry degradation due to differential settlement of ballast/subgrade-numerical prediction by an iterative procedure. J Sound Vib 412:441-456

14. Wang H, Markine V (2018) Corrective countermeasure for track transition zones in railways: adjustable fastener. Eng Struct 169:1-14

15. Berggren E (2009) Railway track stiffness: dynamic measurements and evaluation for efficient maintenance, Dissertation, KTH Royal Institute of Technology, Stockholm

16. Kim H (2016) Trackside measurement of critical zones in railway tracks. Dissertation, University of Birmingham

17. Kaewunruen S, Janeliukstis R, Freimanis A et al (2018) Normalised curvature square ratio for detection of ballast voids and pockets under rail track sleepers. J Phys: Conf Ser 1106(1):012002

18. Gao Z, Dersch M S, Qian Y et al (2017) Use of ballast support condition back-calculator for quantification of ballast pressure distribution under concrete sleepers. In: Proceedings of the 10th international conference on the bearing capacity of roads, railways and airfields, BCRRA 2017 pp. 1955-1960

19. Qian Y, Dersch MS, Gao Z et al (2019) Railroad infrastructure 4.0: development and application of an automatic ballast support condition assessment system. Transp Geotech 19:19-34

20. Zhang Y, Wang L, Zhao H et al (2019) Detection of damaged supports under railway track using dynamic response of a passing vehicle. Int J Struct Stab Dyn 19(10):1950117

21. Balouchi F, Bevan A, Formston R (2016) Detecting railway under-track voids using multi-train in-service vehicle accelerometer. In: 7th IET conference on railway condition monitoring, Birmingham, UK

22. Vidovic I, Landgraf M (2019) Higher railway track availability achieved with innovative data analytics. In: Proceedings: international heavy haul association conference Narvik pp. 299-306

23. Landgraf M, Hansmann F (2018) Fractal analysis as an innovative approach for evaluating the condition of railway tracks. Proc Inst Mech Eng Part F: J Rail Rapid Transit 233(6):596-605

24. Boehm T, Weiss N (2017) Predictive analytics for railwaymonitoring and maintaining point health with smart sensors and AI. ETR 5:42-45

25. Lazarević L, Vučković D (2018) Assessment of sleeper stability in ballast bed using micro-tremor sampling method. In: Murgul V, Pasetti M (eds) International Scientific Conference Energy 
Management of Municipal Facilities and Sustainable Energy Technologies EMMFT 2018, 10-13 December, Samara, Russia

26. Lazarević L, Vučković D, Popović Z (2015) Assessment of sleeper support conditions using micro-tremor analysis. Proc Inst Mech Eng Part F J Rail and Rapid Transit 227(6):657-667

27. Pang Y, Lingamanaik S, Chen B, Yu S (2020) Measurement of deformation of the concrete sleepers under different support conditions using non-contact laser speckle imaging sensor. Eng Struct 205:110054

28. Milne D, Pen LL, Powrie W et al (2018) Automated processing of railway track deflection signals obtained from velocity and acceleration measurements. Proc Inst Mech Eng Part F J Rail Rapid Transit 232(8):2097-2110
29. Kaewunruen S, Aikawa A, Remennikov A (2019) The importance of 'dynamics' in the design and performance-based testing criteria for railway track components. Proc Struct Integrity 21:83-90

30. Sysyn M, Gerber U, Gruen D et al (2019) Modelling and vehicle based measurements of ballast settlements under the common crossing. Eur Transp 71:1-25

31. Steinike L (2005) Bewertung und Ermittlung der Gleissteifigkeit von Straßenbahnoberbaukonstruktionen, Dissertation, TU Dresden

32. Kurhan D (2017) Methodology for calculating the railway track at interaction with fast-speed rolling stock. Dissertation, Dnipropetrovsk National University of Railway Transport, Dnipropetrovsk Oblast 